\title{
Carnosine Treatment for Gulf War Illness: A Randomized Controlled Trial
}

\author{
James N. Baraniuk ${ }^{1}$, Suliman El-Amin ${ }^{1}$, Rebecca Corey ${ }^{1}$, Rakib U. Rayhan ${ }^{1} \&$ Christian R. Timbol $^{1}$ \\ ${ }^{1}$ Divison of Rheumatology, Immunology and Allergy, Georgetown University, Washington DC, USA \\ Correspondence: James N. Baraniuk, Divison of Rheumatology, Immunology, and Allergy, Room 3004F, 3PHC \\ Building, Georgetown University, 3800 Reservoir Rd NW, Washington DC 20007-2197, USA. Tel: \\ 1-202-687-8231. Fax: 1-202-687-9886. E-mail: baraniuj@georgetown.edu
}

\author{
Received: January 15, 2013 Accepted: February 1, 2013 Online Published: February 4, 2013 \\ doi:10.5539/gjhs.v5n3p69 URL: http://dx.doi.org/10.5539/gjhs.v5n3p69
}

\begin{abstract}
About 25\% of 1990-1991 Persian Gulf War veterans experience disabling fatigue, widespread pain, and cognitive dysfunction termed Gulf War illness (GWI) or Chronic Multisymptom Illness (CMI). A leading theory proposes that wartime exposures initiated prolonged production of reactive oxygen species (ROS) and central nervous system injury. The endogenous antioxidant L-carnosine ( $\beta$-alanyl-L-histidine) is a potential treatment since it is a free radical scavenger in nervous tissue. To determine if nutritional supplementation with L-carnosine would significantly improve pain, cognition and fatigue in GWI, a randomized double blind placebo controlled 12 week dose escalation study involving 25 GWI subjects was employed. L-carnosine was given as 500,1000 , and $1500 \mathrm{mg}$ increasing at 4 week intervals. Outcomes included subjective fatigue, pain and psychosocial questionnaires, and instantaneous fatigue and activity levels recorded by ActiWatch Score devices. Cognitive function was evaluated by WAIS-R digit symbol substitution test. Carnosine had 2 potentially beneficial effects: WAIS-R scores increased significantly, and there was a decrease in diarrhea associated with irritable bowel syndrome. No other significant incremental changes were found. Therefore, 12 weeks of carnosine $(1500 \mathrm{mg})$ may have beneficial cognitive effects in GWI. Fatigue, pain, hyperalgesia, activity and other outcomes were resistant to treatment.
\end{abstract}

Keywords: clinical trial, Chronic Fatigue Syndrome, homocarnosine, digit symbol substitution test

\section{Introduction}

Gulf War illness (GWI) is a multisymptom disorder affecting an estimated $25 \%$ of the 700,000 military veterans of the First Persian Gulf War (1990-91) (Fukuda et al., 1998; Kang, Li, Mahan, Eisen, \& Engel, 2009; Research Advisory Committee on Gulf War Veterans' Illnesses [RAC-GWVI], 2008). GWI veterans have a wide spectrum of "functional" complaints including disabling fatigue, diffuse musculoskeletal pain, gastrointestinal dysfunction, sleep abnormalities, and cognitive impairments (Spencer et al. 1998; McCauley et al. 2002; Steele 2000). Neurological dysfunction may be a common pathophysiological mechanism. This would be consistent with the hypothesis that war time exposures to combinations of low levels of sarin and other nerve gas agents, the acetylcholinesterase inhibitor pyridostigmine bromide, organophosphate and other pesticides, particulate and volatile organic compounds in smoke from oil-well fires, depleted uranium, immune activation by simultaneous administration of multiple vaccines and their adjuvants, and stressors of deployment to a hot, dry, dehydrating environment may have acted synergistically to initiate central nervous system injury (RAC-GWVI, 2008; Steele, Sastre, Gerkovich, \& Cook, 2012; Glass et al., 2006; Hernández et al., 2012; Harley et al., 2011; Block et al., 2004). Stressors combined with pyridostigmine bromide, N, N-diethyl-m-toluamide (DEET), and permethrin can disrupt the blood brain barrier and cause neuron death in animal models (Abdel-Rahman, Shetty, \& Abou-Donia, 2002). Reactive oxidant species (ROS) may mediate the neuronal damage (Golomb, 2008; Li, Shou, Borowitz, \& Isom, 2001).

If ROS production is a continued component of GWI neuropathology, then brain antioxidants may have a critical protective role. Differences in production or turnover of endogenous or supplemental antioxidants may be one factor that discriminates between veterans who have developed GWI and those without the syndrome. L-Homocarnosine ( $\gamma$-aminobutyric acid - L-histidine) is the premier antioxidant dipeptide in the brain. Unfortunately, this chemical is not available for clinical use. L-Carnosine ( $\beta$-alanine-L-histidine) is a closely 
related dipeptide that may scavenge ROS in the central nervous system (Boldyrev, Dupin, Bunin, Babizhaey, \& Severin, 1987; Kohen, Yamamoto, Cundy, \& Ames, 1988) and act as an antioxidant and buffering ion in muscle and possibly other peripheral tissues (Abe, 2000; Holliday \& McFarland, 2000). Carnosine may promote brain health because autistic children taking $800 \mathrm{mg}$ a day demonstrated significant cognitive improvements (Chez et al., 2002). This suggested that carnosine may cross the blood brain barrier.

The primary aims of this pilot Phase I/II study were to determine if carnosine improved activity and instantaneous fatigue scores (ActiWatch Score accelerometer device, MiniMiter, Bend, OR) (Gironda, Lloyd, \& Clark, 2007; Kim et al., 2010), Chronic Fatigue Syndrome (CFS) Severity Score (Baraniuk, Clauw, \& Gaumond, 1998; Baraniuk, Naranch, Maibach, \& Clauw, 2000) pain and tenderness (dolorimetry) (Naranch et al., 2002) and quality-of-life domains (Sherbourne, 1995) compared to placebo in GWI subjects. Psychometric and cognitive measures were secondary outcomes.

\section{Materials and Methods}

\subsection{Study Design}

This randomized double blind placebo controlled pilot study of carnosine (500 mg capsules, Village Green Apothecary, Bethesda, MD; Food and Drug Administration Investigational New Drug FDA IND \# 101,700) versus indistinguishable microcrystalline cellulose capsules was tested as add-on therapy in GWI. Dose escalation started with $500 \mathrm{mg}$ once daily, and increased to $500 \mathrm{mg}$ twice daily, and then $1,000 \mathrm{mg}$ in the morning and $500 \mathrm{mg}$ in the evening $(1,500 \mathrm{mg} /$ day) at 4 week intervals (ClinicalTrials.gov identifier NCT00810368). Sets of $4 \times 100$ capsule bottles were prepared and blocks with 3 placebo and 3 carnosine sets randomly mixed. Each set was assigned a sequential 6 digit alpha-numerical identification code so study drug could be dispensed by research pharmacists not involved in blinding the study. After the week 12 visit, the 3 capsules per day were tapered by 1 per week until discontinued. The study was approved by the Georgetown University Institutional Review Board (ID \# 2008-068). Data analysis, recruitment, protocol implementation, and patient participation all occurred at Georgetown University Medical Center and Hospital in Washington, D.C. of the United States.

The planned sample size of $\mathrm{n}=13$ subjects completing each arm was based on individual incremental improvements $(\Delta)$ in the primary outcomes of: (i) CFS Severity Score $(\Delta \geq 5 / 32)$ (Baraniuk et al., 1998; Baraniuk et al., 2000a; Baraniuk, Naranch, Maibach, \& Clauw, 2000b); (ii) instantaneous fatigue ( $\Delta \geq 2$ using the 0 to 10 point ordinal scale) (Kim et al., 2010); (iii) activity levels $(\Delta \geq 20 \%)$ using ActiWatch Score accelerometer devices (Gironda et al., 2007); and (iv) increased accuracy of 4 / 35 letters on 2-back working memory tasks performed during fMRI testing (Owen, 2005; Caseras et al., 2006; Altman, 1991; Altman, 1982; Cohen, 1988) (The 2-back tests and fMRI results will be reported elsewhere). Secondary outcomes are described below. Stringent, conservative criteria for significant treatment responses required: (a) balanced groups with comparable week 0 values, (b) significant improvement with carnosine but not placebo by 2 -tailed paired Student's t-tests $(\mathrm{p} \leq 0.05)$, and (c) significant differences between the 2 treatment responses at week $12(\mathrm{p} \leq$ 0.05 by 2 -tailed unpaired Student's t-tests). Fisher's Exact test was used when required. Data were reported as means and incremental changes $(\Delta)$ between weeks 0 and $12 \pm$ standard deviations (SD).

\subsection{Subject Recruitment}

Subjects were recruited by on-line and newspaper advertisements, and other contacts. Telephone informed consent was obtained to determine eligibility and contact information. GWI subjects were eligible if they met the 1998 CDC criteria (Fukuda et al., 1998; RAC-GWVI, 2008) or had been diagnosed with chronic fatigue syndrome after Persian Gulf deployment (Gray, Reed, Kaiser, Smith, \& Gastanaga, 2002). Exclusions included active military personnel, pregnant women, children, persons suffering from major chronic illnesses or psychiatric disorders, and persons with metal implants or other exclusions from fMRI testing (Fukuda et al., 1998; Kang et al., 2009; RAC-GWVI, 2008; Spencer et al., 1998; McCauley et al., 2002; Steele, 2000).

\subsection{Study Questionnaires}

The CFS Severity score allowed subjects to score the cardinal features of fatigue, cognition, sore throat, lymph nodes, myalgia, arthralgia, sleep and exertional exhaustion (Fukuda et al., 1994; Reeves et al., 2003; Reeves et al., 2005) as none (0), trivial (1), mild (2), moderate (3), or severe (4) (Baraniuk et al., 1998; Baraniuk et al., 2000a; Naranch et al., 2002; Wasserfallen, Gold, Schulman, \& Baraniuk, 1999). The maximum sum for this severity score was 32. Medical Outcome Survey Short Form 36 (SF-36) domains were assayed for changes in quality of life (Ware \& Sherbourne, 1995). Additional secondary symptom and psychometric questionnaires were completed to corroborate and expand data on GWI symptom co-variance and overlap with other syndromes 
(see Supplementary online material, SOM). The instruments were assessed for magnitudes, standard deviations, and reproducibility between weeks 0 and 12 to determine which may be of value for future studies. Subjects could complete the questionnaires on paper or our on-line, Google-based system. Each subject received a personal log-in, password and confidential identification code to access and score the questionnaires (Zheng et al., 2011a; Zheng et al., 2011b). No personal identifying information was collected over the internet. All data were stored in confidential fashion on a password protected computer.

\subsection{Study Visits}

If eligible, subjects came to the Clinical Research Unit, Georgetown University Hospital, Washington, D.C., for their screening visit. After reviewing the study protocol and participant responsibilities, subjects gave written informed consent for participation. Mental competence was assured by Mini-Mental Status examination (Folstein, Folstein, \& McHugh, 1975). History was confirmed using a scripted interview that included diagnostics for CFS (Fukuda et al., 1994), fibromyalgia (Wolfe et al., 1990; Wolfe et al., 2010), myalgic encephalomyelitis (ME) (Carruthers et al., 2011), irritable bowel syndrome (Lea, Hopkins, Hastleton, Houghton, \& Whorwell, 2004; Kurland, Coyle, Winkler, \& Zable, 2006) and migraine (Headache Classification Subcommittee of the International Headache Society, 2004; Ravindran, Zheng, Timbol, Merck, \& Baraniuk, 2011).

Subjects had physical examination, counting of manual tender points (Wolfe et al., 1990) and dolorimetry (Naranch et al., 2002). Screening blood work was drawn for HIV, pregnancy, blood counts, transaminases, and markers of inflammation. Cognitive function was assessed by Trail Making tests A and B (Corrigan \& Hinkeldey, 1987) and digit symbol substitution test (Joy, Fein, Kaplan, \& Freddman, 2000). Subjects toured the Center for Function and Molecular Imaging (CFMI) and practiced 0- and 2-back testing until they felt competent. They returned later for their fMRI with cognitive testing.

Subjects wore ActiWatch-Score wrist devices (Gironda et al., 2007) for the first 2 weeks of the study, and weeks 12 to 14 . In preliminary tests, it was difficult to discriminate between periods of rest and sleep related to chronic fatigue and sedentary work (e.g. computer) performed by control subjects. Diaries were consulted to confirm periods of rest and sleep. Average accelerometer values for each 1 hour epoch during sedentary periods were < 40 units (mean +2 standard deviations). This threshold distinguished "rest" from "active" periods. Records were reviewed for times when the watches were removed (zero activity). The percent of active epochs (\% Active Time) during the entire time the devices were worn was used as an outcome variable. The average activity levels during active periods were also calculated on the assumption that treatment may be associated with more vigorous or prolonged movement. The Score alarm buzzed randomly at approximately 1 hour intervals to remind subjects to grade their instantaneous fatigue on a scale of 0 (no fatigue) to 10 (worst fatigue in life) (Kim et al., 2001). The average fatigue score for each day and the standard deviations and coefficients of variation were calculated to assess the magnitude of daily fluctuations in this symptom, and the trends for fatigue within each 2 week period.

Contact was maintained during the study by telephone and e-mail. Subjects who developed adverse events or discontinued participation were quizzed for their rationale. Symptoms, laboratories, and questionnaires were assessed at the week 6 safety visit. The week 12 visit followed the same format as week 0 .

\section{Results}

\subsection{Subjects and Adverse Events}

Between February 2008 and November 2011 a total of 358 subjects were contacted about participation. Two hundred were interested and began the verbal screening process. Thirty-four subjects were enrolled and randomized. Nine subjects did not complete the study. Two were terminated. One developed an exacerbation of their typical severe musculoskeletal costochondritic chest pain, but was referred by their primary care physician to a cardiologist (Grade 1 adverse event, not related). Another was found to have elevated globulins at week 6 . This participant did not return for follow-up or respond to any inquiries, and was lost to contact (Grade 2 adverse event, not related). Three subjects stopped participation within the first 2 weeks of the study and did not reply to any inquiries.

Three subjects did not want to continue in the study after they reached the 6 week mark because they were frustrated by the absence of any improvements. One moved away after 8 weeks. One subject was found to have an asymptomatic elevation of alanine-serine transaminase plus interval increase in CRP (remained in normal range). As per protocol, study drug was discontinued for 2 weeks. Hepatitis A, B and C serologies were negative, and tests normalized. Study drug was restarted and no alterations in symptoms or blood tests developed. This 
was considered a Grade 1 adverse event not related to study drug. Seven of these responses were in carnosine subjects, with two that dropped out after 6 weeks being on placebo. There were no demographic differences between the carnosine and placebo treated subjects who were enrolled or who completed the study (Table 1).

Table 1. Demographics

\begin{tabular}{lll}
\hline Treatment Group & Carnosine & Placebo \\
\hline Total (N) & 12 & 13 \\
Adverse Effect & 0 & 1 \\
Mean Age ( \pm SD) & $51.8 \pm 11.6$ & $47.2 \pm 8.7$ \\
Male N & $8(67 \%)$ & $9(64 \%)$ \\
Female N & $4(33 \%)$ & $5(36 \%)$ \\
BMI $\left( \pm\right.$ SD) $\mathbf{~ k g} / \mathbf{m}^{2}$ & $31.5 \pm 4.3$ & $30.3 \pm 5.7$ \\
\hline
\end{tabular}

As shown in Table 1, subjects who completed the twelve week protocol. BMI=Body Mass Index, $\mathrm{SD}=\mathrm{Standard}$ Deviation. 17 out of $25(68 \%)$ participants were male.

\subsection{Cognition}

The WAIS-R digit symbol substitution test (Joy et al., 2000) was the only instrument to show a significant carnosine-related change in score. The carnosine treatment group scores improved significantly between week 0 and week 12 ( $\mathrm{p}=0.0018$ uncorrected, 0.046 corrected) while the placebo group showed no change (Figure 1). The week 12 - week 0 incremental changes were significantly different between the carnosine and placebo groups $(p=0.013$, unpaired $t$-test, uncorrected). The carnosine group had arithmetically lower scores at week 0 than the placebo group $(\mathrm{p}=0.089)$, while average scores were equal at week $12(\mathrm{p}=0.66)$. This may have indicated that the week 0 scores were unbalanced between the 2 treatment groups. Although highly suggestive, our conservative criteria did not allow this to be considered conclusive evidence for a beneficial carnosine treatment effect on cognition. Post-hoc analysis indicated that sample sizes of 100 per group would show a significant benefit at 12 weeks $(\mathrm{p}<0.05$ corrected, power $>80 \%)$ if the week 0 average scores were equal, and the incremental increases remained 10.8 for carnosine and 2.7 for placebo. Trail Making tests were not different between weeks or groups.

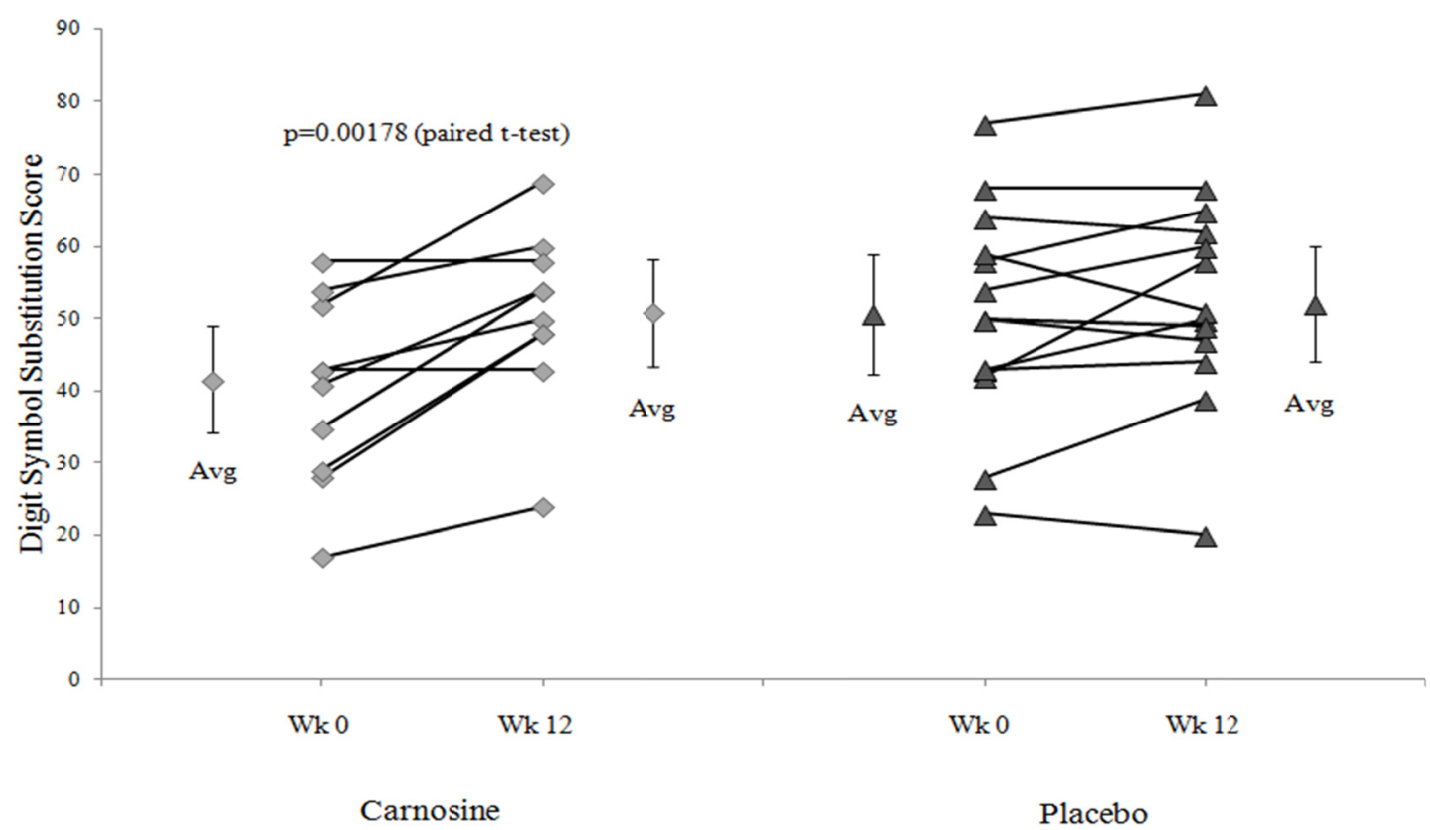

Figure 1. WAIS-R Digit Symbol Substitution scores for wk12 - wk0 $(\Delta)$ 
The incremental change between weeks 12 and $0(\Delta)$ was significant by paired t-tests for the carnosine group (diamonds, average $\pm 95 \%$ CI on the left and right) ( $\mathrm{p}=0.0018$ uncorrected) but not for the placebo group (triangles, average $\pm 95 \% \mathrm{CI}$ on the left and right). The magnitude of the changes was larger for the carnosine than placebo treatment ( $\mathrm{p}=0.013$ uncorrrected). Week 0 scores were higher for placebo (triangles) than carnosine (diamonds) $(\mathrm{p}=0.089)$, but were nearly identical at week 12 .

\subsection{Activity and Instantaneous Fatigue}

Compliance was variable in both treatment groups. Chief complaints were poor comfort and loudness of the alarm prompt. The \% active time was equivalent for the 2 groups and at both time points (Figure 2). Average activity levels were not affected. Instantaneous fatigue ratings showed surprisingly wide variations between GWI individuals (Figure 3). Fatigue levels were not altered in either treatment group and throughout both observation periods since the standard deviations for each subject were small and not related to fatigue severity. This emphasized the need to examine incremental changes as treatment outcomes rather than group differences.

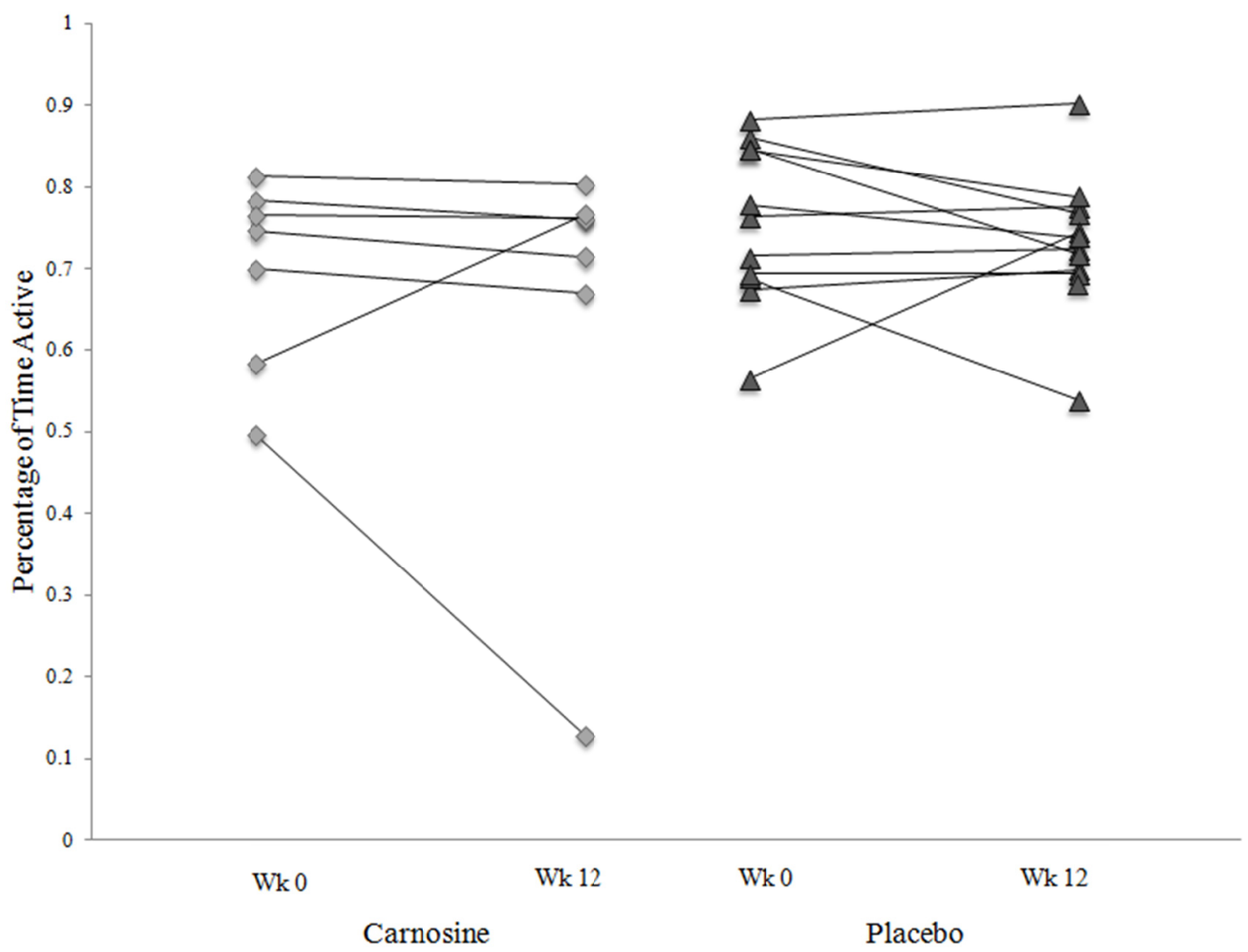

Figure 2. Percent of time active

The percent of time active (accelerometer scores averaged each hour $\geq 40$ units) was comparable for the carnosine (diamonds) and placebo (triangles) groups during the initial and final recording periods. The outlier in the carnosine group did not wear the watch for most of the second period. 
A.

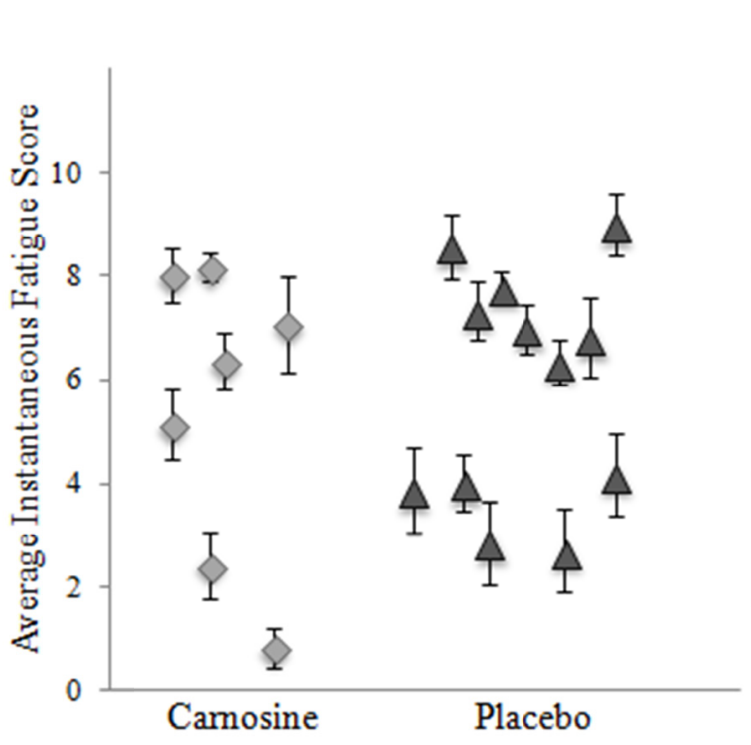

B.

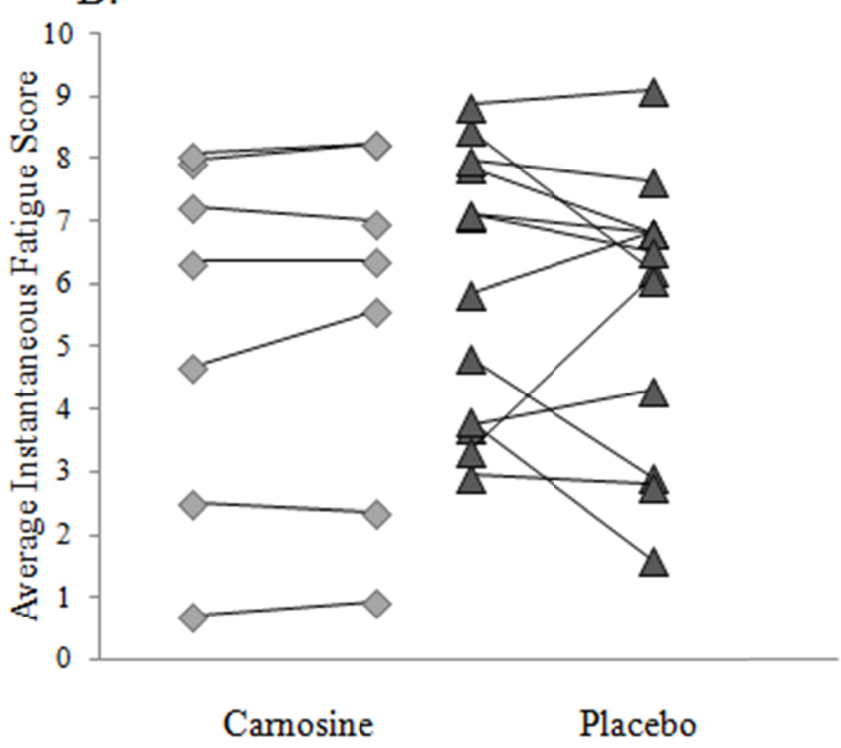

Figure 3. Instantaneous Fatigue Scores

A. The average instantaneous fatigue scores and $95 \%$ confidence intervals from all measurements were shown for all subjects. Fatigue was a stable variable without large excursions (small Cl's) within individuals during the recording periods. B. There was a wide range of instantaneous fatigue scores within the carnosine (diamonds) and placebo (triangles) groups. Individual responses did not change between the two recording periods. There were no treatment effects.

\subsection{Questionnaires}

None of the variables of the CFS Severity Score were altered by treatments, nor were scores different between treatment groups (see SOM). These complaints were robust, reproducible, and resistant to current therapies. The results corroborated the instantaneous fatigue scores. SF-36 domain scores ranged from 65 for Physical Functioning to 11 for Vitality. This indicated significant, persistent disability in GWI over the 3 months of this study. There were no significant incremental differences for any of the questionnaires or their domain scores (SOM table).

\subsection{Irritable Bowel Syndrome}

Gastrointestinal complaints were assessed using Rome II criteria (Lea et al., 2004). At week 0, the carnosine group had $50 \%$ mixed, $0 \%$ constipation and $20 \%$ diarrhea predominant, and $30 \%$ with no irritable bowel syndrome. After 12 weeks, the proportions changed significantly to $14 \%$ mixed, $29 \%$ constipation, $14 \%$ diarrhea and $43 \%$ no irritable bowel syndrome ( $p=0.019$ by Fisher's Exact test). The placebo group had no changes (38\% mixed, $10 \%$ constipation, $19 \%$ diarrhea, $33 \%$ no irritable bowel syndrome). Carnosine reduced stool frequency and watery consistency while placebo did not.

\subsection{Dolorimetry}

Average pain thresholds were not altered by carnosine $(\Delta=-0.18 \mathrm{~kg}$ (SD 0.34)) or placebo $(\Delta=-0.67 \pm 1.73 \mathrm{~kg})$ treatments. The average of all measurements for GWI $(3.32 \pm 2.28 \mathrm{~kg})$ was significantly lower than healthy controls from a parallel study $(5.11 \pm 2.77 \mathrm{~kg} ; \mathrm{n}=14 ; \mathrm{p}=0.035$ by 2-tailed unpaired Student's t-test). Pain thresholds were stable over the 3 month period, and may be a robust outcome measure to assess treatment effects on the neural plasticity associated with pain perception and as a long-term indicator of nociception, hyperalgesia, and central sensitization (Latremoliere \& Woolf, 2009; Pietrobon, 2005; Baron, 2006).

\section{Discussion}

Carnosine treatment was associated with increased digit symbol substitution scores suggesting a cognitive benefit. This test has been associated with activation of the fronto-parietal brain network (Usui et al., 2009; 
Geake \& Hansen, 2010). In contrast, there were no changes for Trail Making tests A and B that may assess inter-hemispheric cognitive processing (Corrigan \& Hinkeldey, 1987). If so, carnosine may have selective trophic or protective effects in discrete brain regions.

Carnosine treatment was also associated with reduced stool frequency indicating an improvement in diarrhea. Other questionnaire outcomes including the primary aims were not altered by either carnosine or placebo treatments. Subjects' levels of complaints were remarkably reproducible between week 0 and week 12 . The symptoms caused significant disability based on SF-36 quality-of-life scores.

The absence of a placebo effect was important because the expectations of improvement did not translate into symptomatic improvement. This steadfast reporting demonstrated that GWI veterans were a highly reliable group who report their symptoms in a reproducible fashion. As a result, beneficial treatment effects in other studies are likely to be true results. The study drug was add-on therapy. The chronic severity of complaints suggests that current treatments had limited therapeutic benefits.

An extensive data set (SOM) was collected for (a) comparisons to CFS subjects, (b) potential characterization of CMI subtypes, (c) post hoc hypothesis generation, (d) selection of appropriate questionnaires for future studies, and (e) sample size calculations. Questionnaires assessed fatigue, pain, and interoceptive complaints such as rhinitis, dyspnea, irritable bladder and irritable bowel syndromes, and perceived responses to irritant exposures.

The cognitive improvement suggested by this study may be analogous to changes in autism. Carnosine given as $800 \mathrm{mg} / \mathrm{d}$ for 8 weeks in double blind, placebo controlled fashion to autistic children significantly improved behavior, socialization, communication and total scores on the Gilliam Autism Rating Scale (Chez et al., 2002). The mechanism(s) may include antioxidant actions via the terminal free amino group of $\beta$-alanine, anticonvulsant properties akin to GABA-ergic agents, chelation of copper and zinc at GABA receptor sites, proton buffering, antioxidant and anti-ischemic protection (Ozonoff, Pennington, \& Rogers, 1991; Trombly, Horning, \& Blakemore, 1998; Stvolinsky \& Dobrota, 2000).

Carnosine improves athletic capabilities, probably due to antioxidant effects or buffering capacity in muscle (Abe, 2000; Holliday \& McFarland, 2000). Physiological stressors acutely increased avian muscle carnosine by 10-fold, but had no effect on brain levels (Manhiani et al., 2011). Similar stressor effects have not been studied in man.

Carnosine is transported across cell membranes by the proton-coupled PepT2 oligopeptide transporter (Jappar, $\mathrm{Hu}$, Keep, \& Smith, 2009). About $14 \%$ is secreted intact into urine within 5 hours (Gardner, Illingworth, Kelleher, \& Wood, 1991). The remainder may be cleaved by the enzyme carnosine dipeptidase 1 and 2 (CNDP1 and CNDP2) (Teufel et al., 2003) in the blood or kidney, or transported into liver, muscle or potentially across the blood brain barrier (Peters et al., 2011).

Carnosine digestion by CNDP1 and CNDP2 releases $\beta$-alanine and histidine. The latter can chelate metals and scavenge singlet oxygen during ischemia (Abe, 2000; Holliday \& McFarland, 2000; Lee et al., 1999). Increased histidine absorption into the brain was hypothesized to trigger an increase in brain homocarnosine synthesis by the rate limiting enzyme ATP-grasp domain-containing protein 1 (ATPGD1) in astroglial cells (Drozak, Veiga-da-Cunha, Vertommen, Stroobant, \& Van Schaftingen, 2010). Lumbar punctures and measurements of histidine, carnosine and homocarnosine in cerebrospinal fluid would be required to confirm this hypothesis.

$\beta$-Alanine is the rate limiting substrate for carnosine synthesis by ATPGD1 in human and equine muscle, since histidine supplements do not boost carnosine levels (Dunnett \& Harris, 1999). $\beta$-Alanine supplementation improved performance in anaerobic muscle testing (Hoffman et al., 2008). $\beta$-Alanine may delay the onset of neuromuscular fatigue in intensively exercising athletes (Artioli, Gualano, Smith, Stout, \& Lancha 2010). Similar effects may not have been evident in our GWI subjects since they were not enrolled in structured aerobic or anaerobic training programs or tested for aerobic exercise capacity as part of this pilot study. High doses of $\beta$-alanine (3 and $6 \mathrm{~g} / \mathrm{d}$ ) improved oxygen utilization during high intensity exercise training in elite athletes (Smith et al., 2009; Walter, Smith, Kendall, Stout, \& Cramer, 2010), although lower doses do not have effects on $\mathrm{VO}_{2 \mathrm{MAX}}$ during aerobic testing.

Oral doses greater than $800 \mathrm{mg}$ of $\beta$-alanine may induce paresthesias (Artioli et al., 2010). This is of relevance to our study since $\beta$-alanine (Shinohara et al., 2004) and ATP may bind Mrgprd receptors of murine dorsal root ganglion neurons that mediate cutaneous mechanical nociception (Cavanaugh et al., 2009). We found a higher drop-out rate in carnosine than placebo treated GWI veterans. They did not report any changes in cutaneous perceptions when questioned, but a subliminal effect cannot be ruled out in those subjects who were lost to contact. Perceptions of enteric interoceptive sensations may have developed based on changes in gastrointestinal 
complaints. At week 0 , half of the carnosine group reported irritable bowel syndrome with mixed diarrhea and constipation, but none had predominantly constipation. However, after 12 weeks constipation was present in $29 \%$, and the rate of mixed diarrhea and constipation had dropped to $14 \%$. The placebo group had no changes in irritable bowel complaints. Although it is important not to over interpret these findings in light of the small sample size, any treatment that would improve the severe gastrointestinal complaints of GWI would be welcomed.

A $\beta$-alanine enriched diet has anxietolytic effects in mice (Murakami \& Furuse, 2010). Scores on the Generalized Anxiety Disorder 7 (GAD-7) (Löwe et al., 2008) and State-Trait Anxiety Inventory (Spielberger, 1985) questionnaires did not change with carnosine treatment. Anxiety was present in $50 \%$ of all CMI subjects based on GAD-7 scores $\geq 10$ (Löwe et al., 2008). Depressive affect was inferred at different rates ranging from $81 \%$ overall using Center for Epidemiological Studies - Depression (CES-D) scores $\geq 16$ (Okun, Stein, Bauman, \& Silver, 1996; Radloff, 1977), 49\% for Beck Depression Inventory (BDI) scores $\geq 17$ (Beck, Steer, Ball, \& Ranieri, 1996; Geisser, Roth, \& Robinson, 1997), and 36\% for major and 21\% for minor depressive affects using the PRIME MD questionnaire (Aiarzaguena, Grandes, Salazar, Gaminde, \& Sánchez, 2008). These high rates were anticipated based on the severity of the symptom profile of these CMI subjects. These states were resistant to carnosine therapy.

The study was limited by the relatively small sample size. The putative treatment effects require validation in similar randomized double blind placebo-controlled studies with larger groups of participants. The small sample size was hampered even further by the nine subjects who withdrew. They had no apparent symptomatic changes or adverse events. This includes parasthesias that have been noted previously (Artioli et al., 2010).

Study compliance was excellent based on diaries and pill counts. However, there were no cerebrospinal fluid, serum, or urine measurements of carnosine, beta-alanine or histidine to confirm absorption, pharmacodynamics, or brain metabolism to homocarnosine. Elevations in brain GABA levels in the treatment group may be identified by molecular spectroscopy (analysis in progress).

Another limitation was the subjective nature of many of the outcome measures. This was by design for this pilot study to assess a broad set of symptomatic and psychometric variables that may have shown beneficial responses to this antioxidant therapy. For instance, even though we observed a possible significant improvement in symptoms of diarrhea, there are several different sets of criteria for IBS, and this treatment effect could be better confirmed with more precise measures for stool form and frequency. In addition, subjects' scores for many questionnaire items were at the upper limits, suggesting possible ceiling effects. Small improvements in their conditions may not have been detectable with the scales employed.

Hyperalgesia and disability leading to inactivity were assessed in semi-objective fashion by dolorimetry and actigraphy, respectively. These outcomes were insensitive to change. It is possible that 12 weeks of add-on therapy without adjunctive treatments was insufficient to reverse the consequences of long duration neural dysfunction. In particular, the chronicity of the subjects' complaints may have made it difficult for them to assess and identify subjective improvements. Established neural patterns may be resistant to modification. Improved understanding of the molecular pathophysiology is required in order to optimally select fMRI and other objective outcome measures for treatment studies such as this one.

\section{Conclusion}

This randomized double blind placebo controlled 12 week dose escalation trial of carnosine showed an increase in digit symbol substitution score and potentially decreased diarrhea in GWI. Similar larger studies with objectively defined and pathophysiologically based outcome measures will be required to confirm and extend these findings.

\section{Acknowledgements}

Support was provided by Department of Defense and follows the directives of the U.S. Army Medical and Materiel Command (USAMRMC) and Human Research protection Office (HPRO) A- 14542.2. All subjects were seen in the Clinical Research Unit where funding has been provided by Federal funds (Grant \# UL1TR000101, previously UL1RR031975) from the National Center for Advancing Translational Sciences (NCATS), National Institutes of Health (NIH), through the Clinical and Translational Science Awards Program (CTSA), a trademark of DHHS, part of the Roadmap Initiative, "Re-Engineering the Clinical Research Enterprise". 


\section{Author Contributions}

J.N.B. designed the protocol. R.U.R, C.R.T. and J.NB recruited participants, administered and conducted the study. R.C., S.E.A, and J.N.B. interpreted and completed clinical data analysis. R.C, S.E.A., and J.N.B. wrote the manuscript. All authors edited the manuscript. None of the authors have financial or non-financial competing interests.

\section{References}

Abdel-Rahman, A., Shetty, A. K., \& Abou-Donia, M. B. (2002). Disruption of the blood-brain barrier and neuronal cell death in cingulate cortex, dentate gyrus, thalamus, and hypothalamus in a rat model of Gulf-War Syndrome. Neurobiology of Disease, 10, 306-326. http://dx.doi.org/10.1006/nbdi.2002.0524

Abe, H. (2000). Role of histidine-related compounds as intracellular proton buffering constituents in vertebrate muscle. Biochemistry (Mosc), 65, 757-765.

Aiarzaguena, J. M., Grandes, G., Salazar, A., Gaminde, I., \& Sánchez, A. (2008). The diagnostic challenges presented by patients with medically unexplained symptoms in general practice. Scand J Prim Health Care, 26, 99-105. http://dx.doi.org/10.1080/02813430802048662

Altman, D. G. (1982). How large a sample? In: Gore SM, Altman DG, editor. Statistics in Practice. London, UK: British Medical Association.

Altman, D. G. (1991). Practical Statistics for Medical Research. London, UK: Chapman \& Hall.

Artioli, G. G., Gualano, B., Smith, A., Stout, J., \& Lancha, A. H. Jr (2010). Role of beta-alanine supplementation on muscle carnosine and exercise performance. Med Sci Sports Exerc, 42, 1162-1173.

Baraniuk, J. N., Clauw, J. D., \& Gaumond, E. (1998). Rhinitis symptoms in chronic fatigue syndrome. Annals Allergy Asthma Immunol, 81, 359-365. http://dx.doi.org/10.1016/S1081-1206(10)63129-8

Baraniuk, J. N., Naranch, K., Maibach, H., \& Clauw, D. (2000a). Irritant rhinitis in allergic, nonallergic, control and Chronic Fatigue Syndrome populations. J CFS, 7, 3-31.

Baraniuk, J. N., Naranch, K., Maibach, H., \& Clauw, D. (2000b). Tobacco sensitivity in Chronic Fatigue Syndrome. $J$ CFS, 7, 33-52.

Baron, R. (2006). Mechanisms of disease: Neuropathic pain - A clinical perspective. Nature Clinical Practice, 2, 95-106. http://dx.doi.org/10.1038/ncpneuro0113

Beck, A. T., Steer, R. A., Ball, R., \& Ranieri, W. (1996). Comparison of Beck Depression Inventories -IA and -II in psychiatric outpatients. $J$ Pers Assess, 67, 588-597. http://dx.doi.org/10.1207/s15327752jpa6703_13

Block, M. L., Wu, X., Pei, Z., Li, G., Wang, T., Qin, L., ... Veronesi, B. (2004). Nanometer size diesel exhaust particles are selectively toxic to dopaminergic neurons: the role of microglia, phagocytosis, and NADPH oxidase. FASEB J, 18, 1618-1620.

Boldyrev, A., Dupin, A. M., Bunin, A., Babizhaey, M., \& Severin, S. (1987). The antioxidative properties of carnosine, a natural histidine containing dipeptide. Biochem Int, 15, 1105-1113.

Carruthers, B. M., van de Sande, M. I., De Meirleir, K. L., Klimas, N. G., Broderick, G., Mitchell, T., ... Stevens, S. (2011). Myalgic Encephalomyelitis (ICD G93.3): International consensus criteria. J Int Med, 270, 327-338. http://dx.doi.org/10.1111/j.1365-2796.2011.02428.x

Caseras, X., Mataix-Cols, D., Giampietro, V., Rimes, K. A., Brammer, M., Zelaya, F., ... Godfrey, E. L. (2006). Probing the working memory system in chronic fatigue syndrome: A functional magnetic resonance imaging study using the n-back task. Psychosom Med, 68, 947-955. http://dx.doi.org/10.1097/01.psy.0000242770.50979.5f

Cavanaugh, D. J., Lee, H., Lo, L., Shields, S. D., Zylka, M. J., Basbaum, A. I., \& Anderson, D. J. (2009). Distinct subsets of unmyelinated primary sensory fibers mediate behavioral responses to noxious thermal and mechanical stimuli. Proc Natl Acad Sci $U$ S A, 106, 9075-9080. http://dx.doi.org/10.1073/pnas.0901507106

Chez, M. G., Buchanan, C. P., Aimonovitch, M. C., Becker, M., Schaefer, K., Black, C., \& Komen, J. (2002). Double-blind, placebo-controlled study of L-carnosine supplementation in children with autistic spectrum disorders. J Child Neurol, 17, 833-837. http://dx.doi.org/10.1177/08830738020170111501

Cohen, J (1988). Statistical power analysis for the behavioral sciences (2nd ed.). Hillsdale, NJ: Lawrence Earlbaum Associates. 
Corrigan, J. D., \& Hinkeldey, N. S. (1987). Relationships between parts A and B of the Trail Making Test. J Clin Psychol, 43, 402-409. http://dx.doi.org/10.1002/1097-4679(198707)43:4<402::AID-JCLP2270430411>3.0. $\mathrm{CO} ; 2-\mathrm{E}$

Drozak, J., Veiga-da-Cunha, M., Vertommen, D., Stroobant, V., \& Van Schaftingen, E. (2010). Molecular identification of carnosine synthase as ATP-grasp domain-containing protein 1 (ATPGD1). $J$ Biol Chem, 285, 9346-9356. http://dx.doi.org/10.1074/jbc.M109.095505

Dunnett, M., \& Harris, R. C. (1999). Influence of oral beta-alanine and L-histidine supplementation on the carnosine content of the gluteus medius. Equine Vet J Suppl, 30, 499-504.

Folstein, M. F., Folstein, S. E., \& McHugh, P. R. (1975). Mini-mental state: A practical method for grading the cognitive state of patients for the clinician. $J$ Psychiatr Res, 12, 189-198. http://dx.doi.org/10.1016/0022-3956(75)90026-6

Fukuda, K., Nisenbaum, R., Stewart, G., Thompson, W. W., Robin, L., Washko, R. M., ... Reeves, W. C. (1998). Chronic multisymptom illness affecting Air Force veterans of the Gulf War. JAMA, 280, 981-988. $\mathrm{http}: / / \mathrm{dx}$. doi.org/10.1001/jama.280.11.981

Fukuda, K., Straus, S. E., Hickie, I., Sharpe, M. C., Dobbins, J. G., \& Komaroff, A. (1994). The chronic fatigue syndrome: A comprehensive approach to its definition and study. International Chronic Fatigue Syndrome Study Group. Ann Intern Med, 121, 953-959.

Gardner, M. L., Illingworth, K. M., Kelleher, J., \& Wood, D. (1991). Intestinal absorption of the intact peptide carnosine in man, and comparison with intestinal permeability to lactulose. $J$ Physiol, 439, 411-422.

Geake, J. G., \& Hansen, P. C. (2010). Functional neural correlates of fluid and crystallized analogizing. NeuroImage, 49, 3489-3497. http://dx.doi.org/10.1016/j.neuroimage.2009.09.008

Geisser, M. E., Roth, R. S., \& Robinson, M. E. (1997). Assessing depression among persons with chronic pain using the Center for Epidemiological Studies-Depression Scale and the Beck Depression Inventory, A comparative analysis. Clin J Pain, 13, 163-170. http://dx.doi.org/10.1097/00002508-199706000-00011

Gironda, R., Lloyd, J., \& Clark, M. (2007). Preliminary evaluation of reliability and criterion validity of Actiwatch-Score. Journal of Rehabilitation Research \& Development, 44, 223-230. http://dx.doi.org/10.1682/JRRD.2006.06.0058

Glass, D. C., Sim, M. R., Kelsall, H. L., Ikin, J. F., McKenzie, D., Forbes, A., \& Ittak, P. (2006). What was different about exposures reported by male Australian Gulf War veterans for the 1991 Persian Gulf War, compared with exposures reported for other deployments? Mil Med, 171, 632-638.

Golomb, B. A. (2008). Acetylcholinesterase inhibitors and Gulf War illnesses. PNAS, 105, 4295-4300. http://dx.doi.org/10.1073/pnas.0711986105

Gray, G. C., Reed, R. J., Kaiser, K. S., Smith, T. C., \& Gastanaga, V. M. (2002). Self-reported symptoms and medical conditions among 11,868 Gulf War-era veterans. Am $J$ Epidemiol, 155, 1033-1044. http://dx.doi.org/10.1093/aje/155.11.1033

Harley, K. G., Huen, K., Schall, R. A., Holland, N. T., Bradman, A., Barr, D. B., \& Eskenazi, B. (2011). Association of organophosphate pesticide exposure and paraoxonase with birth outcome in Mexican-American women. PLoS One, 6(8), e23923. http://dx.doi.org/10.1371/journal.pone.0023923

Headache Classification Subcommittee of the International Headache Society. (2004). The International Classification of Headache Disorders (2nd edition). Cephalalgia, 24(Suppl 1), 9-160.

Hernández, A. F., Parrón, T., Tsatsakis, A. M., Requena, M., Alarcón, R., \& López-Guarnido, O. (2012). Toxic effects of pesticide mixtures at a molecular level: Their relevance to human health. Toxicology, 2012 Jun 21. (Epub ahead of print.)

Hoffman, J. R., Ratamess, N. A., Faigenbaum, A. D., Ross, R., Kang, J., Stout, J. R., \& Wise, J. A. (2008). Short-duration beta-alanine supplementation increases training volume and reduces subjective feelings of fatigue in college football players. Nutr Res, 28, 31-35. http://dx.doi.org/10.1016/j.nutres.2007.11.004

Holliday, R., \& McFarland, G. A. (2000). A role for carnosine in cellular maintenance. Biochemistry (Mosc), 65, 843-848. 
Jappar, D., Hu, Y., Keep, R. F., \& Smith, D. E. (2009). Transport mechanisms of carnosine in SKPT cells: contribution of apical and basolateral membrane transporters. Pharm Res, 26, 172-181. http://dx.doi.org/10.1007/s11095-008-9726-9

Joy, S., Fein, D., Kaplan, E., \& Freddman, M. (2000). Speed and memory in WAIS-R-NI Digit Symbol performance among healthy older adults. Journal of the International Neuropsychological Society, 6, 770-780. http://dx.doi.org/10.1017/S1355617700677044

Kang, H. K., Li, B., Mahan, C. M., Eisen, S. A., \& Engel, C. C. (2009). Health of US veterans of 1991 Gulf War: A follow-up survey in 10 years. $J$ Occup Environ Med 51, 401-410. http://dx.doi.org/10.1097/JOM.0b013e3181a2feeb

Kim, E., Lovera, J., Schaben, L., Melara, J., Bourdette, D., \& Whitman, R. (2009). Novel method for measurement of fatigue in multiple sclerosis: Real-Time Digital Fatigue Score. Journal of Rehabilitation Research \& Development, 47, 477-484. http://dx.doi.org/10.1682/JRRD.2009.09.0151

Kohen, R., Yamamoto, Y., Cundy, K. C., \& Ames, B. N. (1988). Antioxidant activity of carnosine, homocarnosine, and anserine present in muscle and brain. PNAS, 85, 3175-3179. http://dx.doi.org/10.1073/pnas.85.9.3175

Kurland, J. E., Coyle, W. J., Winkler, A., \& Zable, E. (2006). Prevalence of irritable bowel syndrome and depression in fibromyalgia. Dig Dis Sci, 51, 454-460. http://dx.doi.org/10.1007/s10620-006-3154-7

Latremoliere, A., \& Woolf, C. J. (2009). Central sensitization: A generator of pain hypersensitivity by central neural plasticity. Pain, 10, 895-926. http://dx.doi.org/10.1016/j.jpain.2009.06.012

Lea, R., Hopkins, V., Hastleton, J., Houghton, L. A., \& Whorwell, P. J. (2004). Diagnostic criteria for irritable bowel syndrome: Utility and applicability in clinical practice. Digestion, 70, 210-213. http://dx.doi.org/10.1159/000082891

Lee, J. W., Miyawaki, H., Bobst, E. V., Hester, J. D., Ashraf, M., \& Bobst, A. M. (1999). Improved functional recovery of ischemic rat hearts due to singlet oxygen scavengers histidine and carnosine. J Mol Cell Cardiol, 31, 113-121. http://dx.doi.org/10.1006/jmcc.1998.0850

Li, L., Shou, Y., Borowitz, J. L., \& Isom, G. E. (2001). Reactive oxygen species mediate pyridostigmine-induced neuronal apoptosis: Involvement of muscarinic and NMDA receptors. Toxicol Appl Pharmacol, 177, 17-25. http://dx.doi.org/10.1006/taap.2001.9283

Löwe, B., Decker, O., Müller, S., Brähler, E., Schellberg, D., Herzog, W., \& Herzberg, P. Y. (2008). Validation and standardization of the Generalized Anxiety Disorder Screener (GAD-7) in the general population. Med Care, 46, 266-274. http://dx.doi.org/10.1097/MLR.0b013e318160d093

Manhiani, P. S., Northcutt, J. K., Han, I., Bridges, W. C., Scott, T. R., \& Dawson, P. L. (2011). Effect of stress on carnosine levels in brain, breast, and thigh of broilers. Poult Sci, 90, 2348-2354. http://dx.doi.org/10.3382/ps.2011-01426

McCauley, L. A., Joos, S. K., Barkhuizen, A., Shuell, T., Tyree, W. A., \& Bourdette, D. N. (2002). Chronic fatigue in a population-based study of Gulf War veterans. Arch Environ Health, 57, 340-348. http://dx.doi.org/10.1080/00039890209601419

Murakami, T., \& Furuse, M. (2010). The impact of taurine- and beta-alanine-supplemented diets on behavioral and neurochemical parameters in mice: Antidepressant versus anxiolytic-like effects. Amino Acids, 39, 427-434. http://dx.doi.org/10.1007/s00726-009-0458-x

Naranch, K., Park, Y-J., Repka-Ramirez, S. M., Velarde, A., Clauw, D., \& Baraniuk, J. N. (2002). A tender sinus does not always mean sinusitis. Otolaryngol Head Neck Surg, 127, 387-397. http://dx.doi.org/10.1067/mhn.2002.129038

Okun, A., Stein, R. E., Bauman, L. J., \& Silver, E. J. (1996). Content validity of the Psychiatric Symptom Index, CES-Depression Scale, and State-Trait Anxiety Inventory from the perspective of DSM-IV. Psychol Rep, 79, 1059-1069. http://dx.doi.org/10.2466/pr0.1996.79.3.1059

Owen, A. M. (2005). N-Back working memory paradigm: A meta-analysis of normative functional neuroimaging studies. Human Brain Mapping, 25, 46-59. http://dx.doi.org/10.1002/hbm.20131

Ozonoff, S., Pennington, B. F., \& Rogers, S. J. (1991). Executive function deficits in high-functioning autistic individuals: Relationship to theory of mind. $J$ Child Psychol Psychiatry, 32, 1081-1103. http://dx.doi.org/10.1111/j.1469-7610.1991.tb00351.x 
Peters, V., Jansen, E. E., Jakobs, C., Riedl, E., Janssen, B., Yard, B. A., ... Köppel, H. (2011). Anserine inhibits carnosine degradation but in human serum carnosinase $(\mathrm{CN} 1)$ is not correlated with histidine dipeptide concentration. Clin Chim Acta, 412, 263-267. http://dx.doi.org/10.1016/j.cca.2010.10.016

Pietrobon, D. (2005). Migraine: New molecular mechanisms. Neuroscientist, 11, 373-386. http://dx.doi.org/10.1177/1073858405275554

Radloff, L. S. (1977). The CES-D Scale, A self-report depression scale for research in the general population. Applied Psychological Measurement, 1, 385-401. http://dx.doi.org/10.1177/014662167700100306

Ravindran, M. K., Zheng, Y., Timbol, C., Merck, S. J., \& Baraniuk, J. N. (2011). Migraine headaches in chronic fatigue syndrome (CFS): Comparison of two prospective cross-sectional studies. BMC Neurol, 11, 30. http://dx.doi.org/10.1186/1471-2377-11-30

Reeves, W. C., Lloyd, A., Vernon, S. D., Klimas, N., Jason, L. A., Bleijenberg, G., ... International Chronic Fatigue Syndrome Study Group. (2003). Identification of ambiguities in the 1994 chronic fatigue syndrome research case definition and recommendations for resolution. BMC Health Serv Res, 3, 25. http://dx.doi.org/10.1186/1472-6963-3-25

Reeves, W. C., Wagner, D., Nisenbaum, R., Jones, J. F., Gurbaxani, B., Solomon, L., ... Heim, C. (2005). Chronic fatigue syndrome - A clinically empirical approach to its definition and study. BMC Med, 3, 19. http://dx.doi.org/10.1186/1741-7015-3-19

Research Advisory Committee on Gulf War Veterans' Illnesses. (2008). Gulf War Illness and the Health of Gulf War Veterans 2008. US Government Printing Office, Washington, DC pp. 29-30, 57. http://www1.va.gov/RAC-GWVI/

Shinohara, T., Harada, M., Ogi, K., Maruyama, M., Fujii, R., Tanaka, H., ... Hinuma, S. (2004). Identification of a G protein-coupled receptor specifically responsive to beta-alanine. J Biol Chem, 279, 23559-23564. http://dx.doi.org/10.1074/jbc.M314240200

Smith, A. E., Walter, A. A., Graef, J. L., Kendall, K. L., Moon, J. R., Lockwood, C. M., ... Stout, J. R. (2009). Effects of beta-alanine supplementation and high-intensity interval training on endurance performance and body composition in men; A double-blind trial. $J$ Int Soc Sports Nutr, 6, 5. http://dx.doi.org/10.1186/1550-2783-6-5

Spencer, P. S., McCauley, L. A., Joos, S. K., Lasarev, M. R., Schuell, T., Bourdette, D., ... Grewenow, R. (1998). U.S. Gulf War Veterans: Service periods in theater, differential exposures, and persistent unexplained illness. Portland Environmental Hazards Research Centre. Toxicol Lett., 102-103, 515-521. http://dx.doi.org/10.1016/S0378-4274(98)00258-6

Spielberger, C. D. (1985). Assessment of state and trait anxiety: Conceptual and methodological issues. South Psychol, 2, 6-16.

Steele, L. (2000). Prevalence and patterns of Gulf War illness in Kansas veterans: Association of symptoms with characteristics of person, place, and time of military service. Am J Epidemiol, 152, 992-1002. http://dx.doi.org/10.1093/aje/152.10.992

Steele, L., Sastre, A., Gerkovich, M. M., \& Cook, M. R. (2012). Complex factors in the etiology of Gulf War Illness: Wartime exposures and risk factors in veteran subgroups. Environ Health Perspect, 120, 112-118. http://dx.doi.org/10.1289/ehp.1003399

Stvolinsky, S. L., \& Dobrota, D. (2000). Anti-ischemic activity of carnosine. Biochemistry (Mosc), 65, 849-855.

Teufel, M., Saudek, V., Ledig, J. P., Bernhardt, A., Boularand, S., Carreau, A., ... Smirnova, T. (2003). Sequence identification and characterization of human carnosinase and a closely related non-specific dipeptidase. $J$ Biol Chem, 278, 6521-6531. http://dx.doi.org/10.1074/jbc.M209764200

Trombly, P. Q., Horning, M. S., \& Blakemore, L. J. (1998). Carnosine modulates zinc and copper effects on amino acid receptors and synaptic transmission. Neuroreport, 9, 3503-3507. http://dx.doi.org/10.1097/00001756-199810260-00031

Usui, N., Haji, T., Maruyama, M., Katsuyama, N., Uchida, S., Hozawa, A., ... Taira, M. (2009). Cortical areas related to performance of WAIS Digit Symbol Test: A functional imaging study. Neuroscience Letters, 463, 1-5. http://dx.doi.org/10.1016/j.neulet.2009.07.048 
Walter, A. A., Smith, A. E., Kendall, K. L., Stout, J. R., \& Cramer, J. T. (2010). Six weeks of high-intensity interval training with and without beta-alanine supplementation for improving cardiovascular fitness in women. $J$ Strength Cond Res, 24, 1199-1207. http://dx.doi.org/10.1519/JSC.0b013e3181d82f8b

Ware, J. E., \& Sherbourne, C. D. (1995). The MOS 36-item short-form health survey (SF-36): I. Conceptual framework and item selection. Medical Care, 30, 473-483. http://dx.doi.org/10.1097/00005650-199206000-00002

Wasserfallen, J. B., Gold, K., Schulman, K. A., \& Baraniuk, J. N. (1999). Item responsiveness of a rhinitis and asthma symptoms score during a pollen season. $J$ Asthma, 36, 459-465. http://dx.doi.org/10.3109/02770909909087288

Wolfe, F., Clauw, D. J., Fitzcharles, M. A., Goldenberg, D. L., Katz, R. S., Mease, P., ... Yunus, M. B. (2010). The American College of Rheumatology preliminary diagnostic criteria for fibromyalgia and measurement of symptom severity. Arthritis Care Res (Hoboken), 62, 600-610. http://dx.doi.org/10.1002/acr.20140

Wolfe, F., Smythe, H. A., Yunus, M. B., Bennett, R. M., Bombardier, C., Goldenberg, D. L., ... Sheon, R. P. (1990). The American College of Rheumatology 1990 Criteria for the Classification of Fibromyalgia. Report of the Multicenter Criteria Committee. Arthritis Rheum, 33, 160-172. http://dx.doi.org/10.1002/art.1780330203

Zheng, Y., Ravindran, M., Adewuyi, O., Di Poto, C., Timbo1, C., Esteitie, R., \& Baraniuk, J. (2011). eZhengtricity (C) 2010: A free novel way to confidentially administer, track, receive and score medical questionnaires instantly. 10th International ME/CFS Conference, Ottawa, Canada, September, 2011.

Zheng, Y., Ravindran, M., Adewuyi, O., Di Poto, C., Timbo1, C., Esteitie, R., \& Baraniuk, J. (2011). eZhengtricity (C) 2010: A free novel way to confidentially administer, track, receive and score medical questionnaires instantly. World Allergy Organization Conference, Cancun, Mexico, December 3-8, 2011 